HANNO EHRLICHER

\title{
Anatomischer Blick und allegorische Schrift. Baltasar Graciáns moralische Anatomie auf der Spur Walter Benjamins gelesen
}

\author{
1. Der offene Körper, der Blick des Anatomen und die Doppeldeutigkeit \\ der Allegorie
}

Beginnen wir mit dem Blick. Denn am Anfang einer spezifisch modernen Anatomie soll nicht das Wort gewesen sein, sondern der Blick, der das Neue schuf. Wenn die Moderne von ihren Gründungsmythen lebt, von den Erzählungen eines heroischen Anfangs, mit dem die menschliche Vernunft ihren Anspruch auf ein eigenes Dasein manifestierte und überhaupt erst Legitimität und Eigenrecht erlangte, ${ }^{1}$ so stellt Andreas Vesalius eine ihrer prominenten Heldenfiguren dar. ${ }^{2}$ Sein Beitrag zum

1 Hans Blumenberg versuchte in seiner Studie zur Legitimität der Neuzeit (Frankfurt a. M., 1966) diesen Autonomieanspruch der Moderne gegen das Säkularisierungstheorem als Umschlagsphänomen aus der Verabsolutierung des Glaubens im mittelalterlichen Nominalismus zu erklären. Die Steigerung Gottes zur ,potentia absoluta", die der menschlichen Vernunft gar nicht mehr einsehbar ist, habe dazu geführt, dass sich der Mensch praktisch in einer nun unzuverlässigen Welt selbst zu behaupten hatte und entsprechende Techniken dafür entwickelte. Wenn Blumenberg dabei für das geschichtliche „Recht“ der Moderne eintritt, das vom Säkularisierungsbegriff in Frage gestellt werde, übergeht er jedoch genau die Paradoxien des Anfangsmomentes selbst, die jede Autorität, und also auch die der Moderne, von innen her bedrohen und auf denen die Dekonstruktion so nachdrücklich insistiert. Vgl. dazu Jacques Derrida. Gesetzeskraft. Der „mystische Grund der Autorität“. Frankfurt a. M., 1991.

2 Die heroisierende Stilisierung von Vesalius als ,Begründer der neuzeitlichen Anatomie' ließe sich als ein nicht abreißender Faden durch die Enzyklopädik der Moderne hindurch verfolgen, von Antoine-Joseph Dézallier d'Argenvilles' langem Eintrag in der Encyclopédie bis zu Wikipedia, wo der Anatom zum Pionier erhoben wird, der ,gegen die allgemeine Überzeugung die Einstellung [vertrat], allein die menschliche Leiche sei als zuverlässiger Weg zur Erkenntnis des Körperbaus zulässig und als Erster [erkannte], dass Galens Arbeiten zur Anatomie sich auf Tiere bezogen“. Quellenstandort online: http://de.wikipedia.org/wiki/Andreas_Vesalius (16.02.2009). 
Fortschritt der Wissenschaften wird gerne als Rebellion gegen ein verstaubtes Buchwissen erzählt, gegen das er erfolgreich den unvoreingenommenen eigenen Blick auf die Tatsachen des Lebens durchgesetzt habe. In Vesalius' Konflikt mit Mathaeus Curtius im Rahmen der Vorlesungen, die dieser zur Anatomia des Mundinus im Januar 1540 in Bologna hielt, spitzt sich der vermeintliche Paradigmenwechsel von textbasierter und autoritätsorientierter ,alter' Anatomie zur blickgestützten, auf experimentell kontrollierte eigene empirische Erfahrung vertrauender ,neuer' Wissenschaft zum Drama zu, ein Drama, von dem wir dank des zeitgenössischen Zeugenberichts des deutschen Studenten Baldasar Heseler wissen. ${ }^{3}$ Beschränken wir uns auf den agonalen Kern- und Höhepunkt des Streites, den differierenden Umgang mit der Autorität Galenus' und dem sichtbaren Material des Körpers:

Now, he said, excellentissime Domine, here we have our bodies. We shall see whether I have made an error. Now we want to look at this and we should in the meantime leave Galen, for I acknowledge that I have said, if it is permissible to say so, that here Galen is in the wrong, because he did not know the position of the vein without pair in the human body, which is the same to-day just as it was in his time: Curtius answered smiling, for Vesalius, choleric as he was, was very excited: No, he said, Domine, we must not leave Galen, because he always well understood everything, and, consequently, we also follow him. [...] Curtius replied: I am no anatomista, but there can be also other veins nourishing the ribs and the muscles besides these. Where, please, Vesalius said, show them to me. Curtius said: Do you want to deny the ducts of Nature? Oh!, Vesalius said, you want to talk about things not visible and concealed. I, again, talk about what is visible. Curtius answered: Indeed, I always deal with what is most obvious [apertissimus]. Domine, you do not well understand Hippocrates and Galen concerning this. Vesalius replied: It is quite true, because I am not so old a man as you are. ${ }^{4}$

Curtius bezieht seinen Evidenzbegriff, das Vertrauen ins Offensichtliche (,,apertissimus“) aus seiner hermeneutischen kognitiven Kompetenz als Leser. Er kennt die Texte der Autoritäten, ihr Sinn steht ihm offen und belegt, für jeden Gelehrten nachvollziehbar, die Richtigkeit seiner Aus-

Ein grand récit vom Fortschritt der Vernunft, der sich nicht nur in populärwissenschaftlichen Handbüchern fortsetzt, sondern ,virtually all historians of anatomy“ kennzeichnet, wie Andrew Cunningham moniert hat, der selbst eine differenziertere Perspektive auf die Renaissance der Anatomie zu etablieren versucht. Vgl. Andrew Cunningham. The Anatomical Renaissance. The Resurrection of the Anatomical Projects of the Ancients. Aldershot, 1997, S. 4.

3 Ruben Eriksson (Hg.). Andreas Vesalius' First Public Anatomy in Bologna 1540. An Eyewitness Report. Upsala u. Stockholm, 1959.

4 Ebd., S. 272. Ich zitiere zur leichteren Verständlichkeit nach der englischen Übersetzung Eriksons, die er dem lateinischen Original beifügt. 
führungen über die Zusammensetzung des menschlichen Körpers. Vesalius dagegen denunziert eben diese offensichtliche Textkenntnis als das okkulte Geheimwissen einer professoralen Elite und hält ihm die Materialität des menschlichen Körper als alternativen Text entgegen, dessen Bedeutung er in seiner Dissektion eigenhändig freigelegt zu haben und nun öffentlich in einer performativen demonstratio ad oculos beweisen zu können glaubt. Ein Einschnitt in der Geschichte der Anatomie fürwahr, insofern Vesalius hier mit den Regeln des universitären Lehrbetriebs und den sozialen Hierarchien bricht und seine Position als untergeordneter, assistierender Chirurg, der die ex cathedra dozierten Wissenselemente nachträglich veranschaulichend $\mathrm{zu}$ verifizieren hat, mit einem spektakulärem coup de theâtre umwertet und sich selbst zum Hauptakteur der Veranstaltung macht. Der Begeisterung und Unterstützung des studentischen Publikums konnte er sich dabei gewiss sein, denn der Schauwert seines auf die Beteiligung aller Sinne abzielenden anatomischen Theaters war allemal höher als der theoretische Frontalunterricht mit Einsatz illustrierender Elemente. Vesalius mobilisiert ja nicht nur die Schaulust seines Publikums, sondern mit dem Tastsinn auch jenen Sinn, der - damals wie heute - als niederes Seelenvermögen im eher platonischen akademischen Lehrbetrieb sonst weitgehend sublimiert werden muss. Diese Neuheit der ,ganzheitlich' orientierten Lehrmethode setzt auch das Frontispiz von Vesalius' De humani corporis fabrica in Szene (vgl. die Abbildung auf S. 6 in diesem Band), auf dem sich der Gelehrte als ein ungemein populärer Schausteller eines Blicks ins menschliche Körperinnere darstellen lässt, ${ }^{5}$ der nicht mehr nur den engen Zirkel eines gelehrten Fachpublikums interessiert, sondern nachgerade zu einem Faszinosum der Massen geworden ist. Der direkte Vergleich mit typischen Darstellungen der tradierten Praxis anatomischer Vorlesungen, wie sie sich aus der Zeit vor Vesalius finden (vgl. Abb. 1), ${ }^{6}$ verdeutlicht die polemische Stoßrichtung der Bildinszenierung: Die Dissektion ist keine niedere, vom Ostensor ausgeübte Handwerkstätigkeit mehr, sondern tragendes Element einer eigenständigen Wissens-

5 Cunningham, von dessen Ausführungen ich im Folgenden weitgehend profitiere, stellt zu Recht fest: „We have no reason to doubt, and many reasons to trust, that Vesalius had as much control over this page as he did over the others". Cunningham (Anm. 2), S. 124.

6 Zur maßgeblich von Mundinus geprägten anatomischen Praxis vor Vesalius vgl. Cunningham (Anm. 2), S. 42ff. Er weist auch darauf hin, dass die in der Bildinszenierung produzierte Gleichzeitigkeit von lectio und demonstratio in der Praxis meist zeitlich separiert erfolgten (S. 44). Für eine ausführliche Bildinterpretation vgl. Jerome J. Bylebyl. „Interpreting the Fasciculo Anatomy Scene“. Journal of the History of Medicine 45 (1990), S. 285-316. 


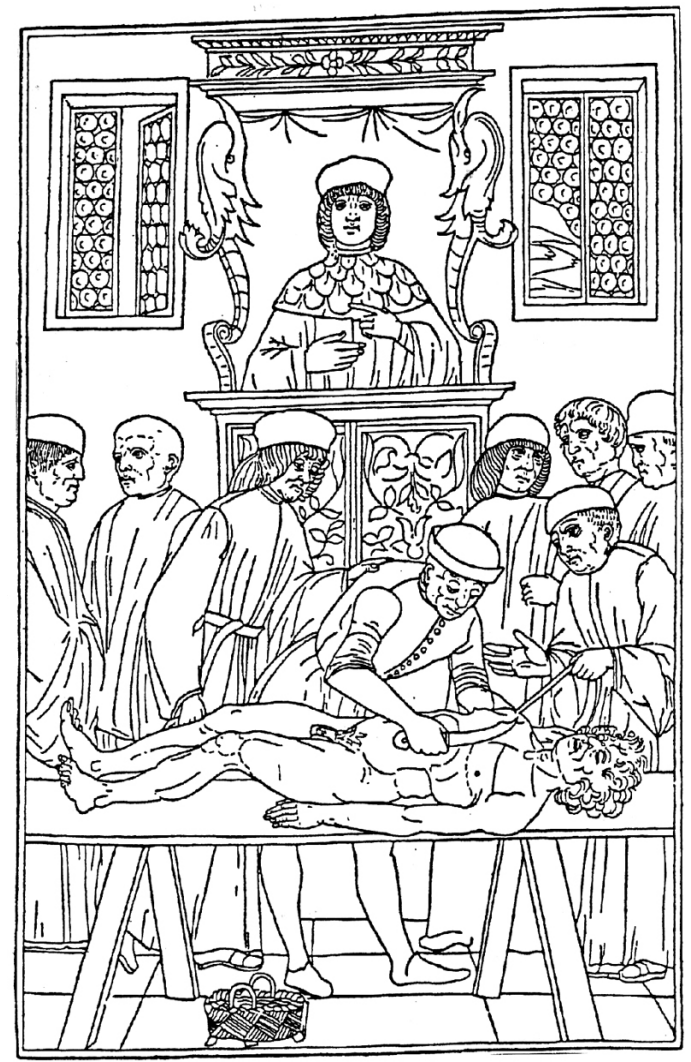

Abb. 1: Anatomische Demonstrationsszene aus Johannes de Ketham. Fasciculo di Medicina (Venedig, 1494).

form, die ihre Evidenz performativ produziert, nicht durch referenziellen Verweis auf eine schon vorhandene Aussage, sondern im Zuge eines Handlungsvollzugs, in dem Zeigegestus und Sprechakt zusammenfallen. Vesalius vereint als erläuternder Chirurg in Personalunion die vormalig arbeitsteilig getrennten Funktionen theoretischer Anschauung und praktischer demonstratio und nimmt als Lehrer ohne Kanzel keine erhöhte Position mehr ein, sondern hat sich auf Augenhöhe mit dem Publikum begeben, das er zur Partizipation an einem sinnlich erfahrbaren Wissen motiviert. Die lectio wird zur Aufführung, wobei nicht nur die trennende Rampe zwischen Bühne und Zuschauerraum überschritten ist, ${ }^{7}$ sondern auch die Schwelle zum Objekt des Wissens, das von den

7 Dies in Analogie zur Situation des Karnevals, den Michail Bachtin als ein Schauspiel ohne Rampe charakterisiert hat. Vgl. Michail M. Bachtin. Literatur und Karneval. Zu Romantheorie und Lachkultur. Frankfurt a. M., 1990, S. 56. Die Nähe 
Zuschauern der vordersten Reihe nicht nur observiert, sondern auch betastet werden kann. Was für moderne Hochschulpädagogen, die in ihren Workshops gerne stärkere affektive und psychomotorische Beteiligung der Lehrenden fordern, zunächst sehr lobenswert aussehen mag, ist ethisch dabei vielleicht nicht ganz unbedenklich, wenn man in den Aufzeichnungen des deutschen Studenten von Vesalius' Vivisektionen am lebenden Tier liest, mit denen sein theatrum anatomicum, das auf die Etablierung eines Rituals des gemeinsam geteilten Erfahrungswissens abzielt, zum Theater der Grausamkeit mutiert:

[F]or surely, Domini, he said, you can learn only little from a mere demonstration, if you yourselves have not handled the objects with your hands, etc. Finally he took a dog [...]. He bound it with ropes to a small beam so that it could not move, similarly he tied his jaws so that it could not bite. Here, Domini, he said, you will see in this living dog the function of the nervi reversivi, and you will hear how the dog will bark as long as these nerves are not injured. Then, I shall cut off one nerve, and half of the voice will disappear, then I shall cut the other nerve, and the voce will no longer be heard. [...] Finally, he said, I shall proceed to the heart, so that you shall see its movement, and feel its warmth, thirdly so that you shall here around the ilium feel the pulse with one hand, and with the other the movement of the heart. And please, tell me, what its movement is, whether the arteries are compressed when the heart is dilated, or whether they in the same time also have the same movement as the heart. I saw how the heart of the dog bounded upwards, and when it no longer moved, the dog instantly died. Those mad Italians pulled the dog at all sides so that nobody could really feel these two movements. But some students asked Vesalius what the true fact about these movements was, what he himself thought, whether the arteries followed the movement of the heart, or whether they had a movement different from that of the heart. Vesalius answered: I do not want to give my opinion, please do feel yourselves with your own hands and trust them.

Die Aufforderung an die Studenten, den Herzschlag des Lebens selbst zu fühlen und so nicht theoretisch vermittelt, sondern konkret-unmittelbar zu begreifen, bezeichnet den phantasmatischen Kern des von Versalius mit durchgesetzten anatomischen Blicks der Frühen Neuzeit: Der Wunsch nach einer totalen Transparenz des Lebenssinns, der nicht zeichenhaftmedialer Natur und damit den Uneindeutigkeiten des Symbolischen ausgesetzt sein soll, sondern manifest, hautnah und sensationell evident. Dass dieser Wunsch auch in der Dissektion des toten Körpers am Werke ist und in der Vivisektion seinen logischen Endpunkt findet, zeigt

von Anatomie und Karneval ist auch historisch belegbar, denn öffentliche anatomische Sektionen fanden teilweise direkt im Anschluss an Karnevalsfeierlichkeiten statt.

8 Eriksson (Anm. 3), S. 290-292 [Herv. d. Verf.]. 
sich auch in der Fabrica in der berühmten Zusammenstellung der acht „tabulae musculorum“, die in ihrer sequentiellen Reihung eine Anatomie des lebendigen Körpers inszenieren. Ohne die begeisternde Beteiligung der Nahsinne stellt sich am Ende dieser Miniaturanatomie jedoch die Frage, was am Ende der anatomischen Zergliederung tatsächlich bleibt: die Transparenz des Lebenssinns oder doch nur ein melancholisches memento mori:

Has an anatomy or a vivisection been performed? This question is provoked by the way the anatomist seems to threaten life - his painful procedure for revealing truths seems to kill them. Though he tells us that he will expose a tangible truth, the anatomist instead turns up the depths, displaces parts form a coherent whole, and flattens out bodies once full with divine significance. [...] Thus the anatomy has a paradoxical doubleness: it is a method for revealing order, but it also causes its decay. ${ }^{9}$

Den vivisektorischen neuzeitlichen Wunsch der Anatomie, das Leben und seinen Sinn durch dessen experimentelle Durchdringung in den Griff zu bekommen, begleitet wie ein Schatten das melancholische christliche Wissen sub specie aeternitatis, dass das menschliche Leben endlich ist und der Tod dem Sinn vorangehen muss, damit sich dieser im Jenseits offenbaren kann. Die Emblematik des memento mori umgibt die Inszenierungen des anatomischen Blicks ins Körperinnere daher nicht zufällig schon von Anfang an und überführt die performativ produzierte Evidenz des Materiellen wieder in ein tradiertes zeichenhaftes Vorwissen. Diese mediale Überführung ist allerdings kein bloßes Zugeständnis an die Autorität der Kirche, wie es überhaupt eine fromme Legende der Aufklärung ist, dass die lange, fast 1200 Jahre währende Absenz anatomischer Praktiken in Europa dogmatischen Bedenken oder direkten Verboten der Amtskirche geschuldet sei. ${ }^{10}$ Sie war auch nicht erst die

9 Devon L. Hodges. Renaissance Fictions of Anatomy. Amherst, 1985, S. 6. Dort findet sich auch die erwähnte Serie von Abbildungen zur Muskulatur aus der $\mathrm{Fa}$ brica (S. 7-14).

10 Die Legende widerlegte bereits Mary N. Alston. „The Attitude of the Church Towards Dissection Before 1500“. Bulletin of the History of Medicine 3 (1944), S. 221238. Gegen die These vom kirchlichen Anatomieverbot argumentiert auch Rafael Mandressi. Le regard de l'anatomiste. Dissections et invention du corps en Occident. Paris, 2003, S. 19-60. Seine Ausführungen zeigen, dass der Widerstand gegen die Zergliederung von Leichen nicht von Seiten der Amtskirche und ihrer Dogmatik kam, sondern in einer viel atavistischeren religiösen Volksfrömmigkeit wurzelte. Die Tatsache, dass trotz fehlender Beweisdokumente bis heute die „Unterbrechung“ der Anatomiepraxis immer wieder einem vermeintlichen „kirchlichen Sektionstabu“ angelastet wird, ist symptomatisch dafür, wie sehr der anatomische Blick unserer Moderne zur naturalisierten Selbstverständlichkeit geworden und habitualisiert ist. Pars pro toto verweise ich nur auf einen neueren Aufsatz von Stefanie Stockhorst, 
Zutat eines nachreformatorischen Barocks, der das optimistische Selbstvertrauen der humanistischen Wissenschaften der Renaissance im Nachhinein wieder mit dem altem Ballast des theologischen Absolutismus beschwert hätte. Vielmehr haftet das memento mori dem vivisektorischen Wunsch der Anatomie nach Erfassung des Lebens von Anfang an als eine Art disphorisches Revers an, das daran erinnert, dass beim Blick in den toten Körper vielleicht doch nicht die Prinzipien des Lebens erkannt werden, sondern nur tautologisch das Vorhandenseins des Todes zu konstatieren ist, und - schlimmer noch - dass Vivisektion nicht nur nichts an der Tatsache des Todes ändert, sondern sie sogar noch im konkreten Einzelfall künstlich beschleunigt. Das melancholische Revers zeigt sich sehr deutlich beispielsweise in Luis Lobera de Avilas Libro de Anatomia, der 1542 erschien und mit einer allegorischen Traumvision eingeleitet wird, in welcher der menschliche Körper bereits vor Vesalius als Bauwerk metaphorisiert ist, konkret als ,torre muy hermosa y muy espaciosa y de maravillosa y sabia fabrica y ordenacion". ${ }^{11}$ Die allegorische Vision Loberas endet mit dem Einsturz des Turmes und genau der moralischen Botschaft des memento mori ${ }^{12}$ die auch auf dem ein Jahr später erschienenen Frontispiz der Erstausgabe von Vesalius' Werk zu erkennen ist, sofern man das Skelett als eine Figuration des Todes versteht, das über dem Seziertisch auf der Ballustrade des oberen Zuschauerrangs des hölzernen Theaters thront und damit in etwa an der Stelle positioniert ist, wo in der alten vor-theatralischen Form der Anatomievorlesung der Lehrende gesessen hatte. Als eine solche Todes-Figur hat es jedenfalls der Künstler interpretiert, der für das in Kleinigkeiten, aber doch wesentlich veränderte Frontispiz der zweiten Auflage der Fabrica von 1555 verantwortlich war: Er stattet das Skelett der ikonographischen Konvention folgend mit einer Sichel aus und macht es so als eine personifizierende Allegorie des Todes kenntlich, während es in der ersten Version durchaus noch als ,realistisches' Accessoire aufgefasst werden konnte, als visuelles didaktisches Hilfsmittel zur Veranschaulichung, wie es Vesalius zusammen mit anderen Medien in seinen Vorlesungen ja tatsäch-

der dieses Klischee wiederholt: „Unterweisung und Ostentation auf dem anatomischen Theater der Frühen Neuzeit“. Zeitsprünge 9 (2005), S. 271.

11 Ich zitiere nach dem Abdruck des Textes, den Luis Alberti López als Appendix seiner Studie präsentiert. La anatomía y los anatomistas españoles del Renacimiento. Madrid, 1948, S. 247.

12, ,[V]erdaderamente esta vision no es otra cosa sino el hombre: y la vida de este mundo y la vejez y la muerte. Por ende, hermanos mios, yo os ruego que mireys muy bien todo esto: pues es necesario morir: temed a Dios y apartaos de hacer mal y hacer bien“. Ebd., S. 255. 

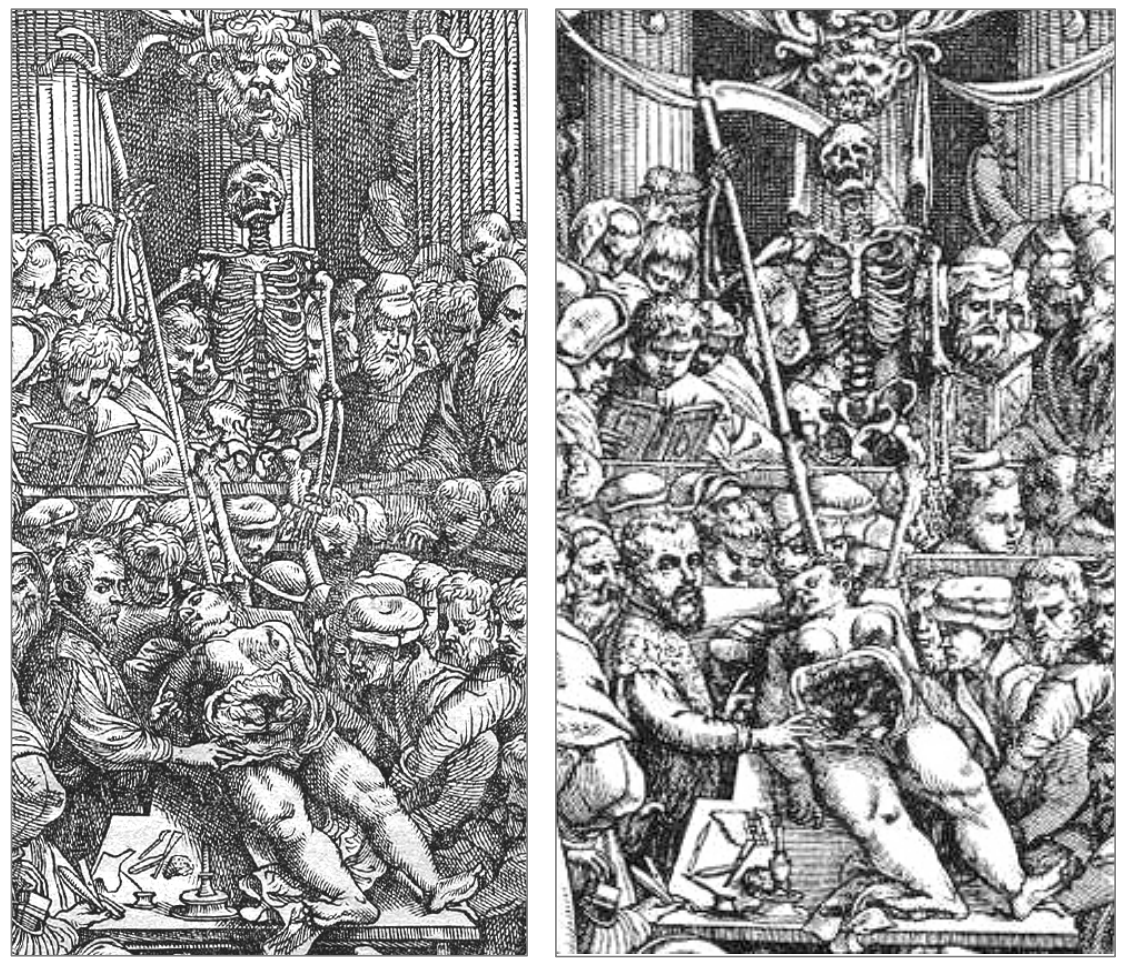

Abb. 2: Skelett auf dem Frontispiz zu Andreas Vesalius. De humani corporis fabrica: links die Ausgabe von 1543 und rechts die Ausgabe von 1555.

lich einsetzte (vgl. Abb. 2). Durch die allegorische Ausdeutung des Skeletts auf dem Frontispiz, die allerdings keineswegs eine Fehldeutung der ersten Version darstellt, sondern in dieser bereits als Möglichkeit angelegt ist, ${ }^{13}$ erhält der Blick ins Körperinnere der Leiche einen Hintersinn: Während Vesalius mit der rechten Hand an das von ihm anatomisch eröffnete Innere des Körpers rührt und so dem Versprechen nach transparenter Unmittelbarkeit und sinnlicher Evidenz Ausdruck gibt, von dem die Anatomie als wissenschaftliche Performance lebt, weist der nach oben gerichteten Zeigefinger auf etwas hin, das mit dem naheliegend sichtbaren Material zugleich anwesend ist und ihm so einen zweiten und ,höheren' Sinn verleiht. Dass das Skelett auf einer vorbereitenden Skizze zum Kupferstich zunächst noch ganz fehlte, nimmt der allegorischen Doppeldeutigkeit des Gestus von Vesalius nichts, sondern ver-

13 Diese Ansicht vertrete ich in Abweichung von Cunninghams Deutung des Titelkupfers, der ich aber insgesamt entscheidende Anstöße verdanke. Vgl. Cunningham (Anm. 2), S. 124-128. 
deutlicht nur die grundsätzliche Struktur des Allegorischen im Medium des Visuellen: Das auf den ersten Blick Gezeigte ist nicht das eigentlich Gemeinte. An dieser Struktur ändert auch die Frage nichts, ob diese Eigentliche nun noch einmal als Figur des Todes in Erscheinung tritt oder im Verborgenen bleibt wie Gott, der in diesem anatomischen Theater der Renaissance, das im Inneren einer Kirche aufgebaut sein könnte, nicht eigens manifest werden muss, um verhüllt angedeutet zu sein. ${ }^{14}$

Im Rahmen einer christlichen Anthropologie blieb die anatomische Praxis der Frühen Neuzeit an ein melancholisches Wissen um die Beschränktheit menschlicher Erkenntnisfähigkeit und Unerreichbarkeit des eschatologischen letzten Sinns zurückgebunden, der von Gott gestiftet und ihm vorbehalten ist. Der Allegorisierung der anatomischen Praxis, die sich im Falle Lobera de Avilas oder der Bildinszenierung auf dem Titelblatt von Vesalius' Fabrica zeigte, kam damit vor allem eine moralisch korrektive Funktion zu. Die performative Eigendynamik der empirokritischen Experimentalwissenschaften wurde gedrosselt und das von ihr produzierte Wissen immer wieder in das tradierte Menschenbild integriert. Umgekehrt zeigt sich aber die epistemologische Dynamik des Experimentellen in der Tendenz zur Übertragung des anatomischen Blicks auf den Bereich des Moralischen, in der ,anatomie morale“, die Louis van Delft als ein Parallelphänomen zur ,anatomie moralisée“ beschrieben hat. ${ }^{15}$ Die Anatomie wird dabei nicht nur als ein besonders modischer Terminus für alle möglichen Anwendungsbereiche geltend gemacht, sondern als ein basales epistemologisches Modell des Blicks ins Innere bestätigt, das sich vom Physischen ins Psycho- und Charakterologische wenden lässt. Baltasar Graciáns Criticón, genauer die neunte „Krisis“ des ersten Teils, ${ }^{16}$ ist in diesem Zusammenhang nicht nur des-

14 Cunningham versucht, das Skelett als realistisches Element zu deuten, und meint, aus seinem Fehlen in der Vorbereitungsskizze schließen zu können, dass es nicht als tragendes Sinnelement intendiert gewesen sein könne. Die These, dass das Skelett nicht gedeutet werde, sondern nur auf den Schöpfergott im Himmel verwiesen werden solle, dessen Werk sich im kleinen Mikrokosmos des Menschenkörper spiegele, lässt sich leicht widerlegen, wenn man berücksichtigt, dass es nicht nur durch Vesalius' Finger, sondern gleich mehrfach angezeigt wird: besonders deutlich von einem Zuschauer links auf dem obersten Geländer, etwas diskreter auch von zwei Zuschauern auf der gleichen Ebene rechts. Wichtig für die Struktur des Allegorischen ist aber ohnehin nicht das konkrete Objekt, das immer nur ein uneigentlicher Stellvertreter ist, sondern die Spannung zwischen zwei kopräsenten Bedeutungsebenen.

15 Vgl. die Kapitel zur „anatomie moralisée“ und zur „anatomie morale“ in Louis van Delft. Littérature et anthropologie. Nature humaine et caractère à l'âge classique. Paris, 1993, S. 183-255.

16 Im Folgenden lege ich die von Antonio Prieto besorgte Studienausgabe zugrunde: 
halb interessant, weil dort der Begriff der „moralischen Anatomie“ explizit eingesetzt wird. An diesem Text lässt sich auch zeigen, dass allegorische Repräsentationstechniken nicht nur dazu eingesetzt werden können, eine vom empirokritischen anatomischen Blick auf die Einzelteile bedrohte Totalität didaktisch wirksam zu reinszenieren, sondern dass dieser Blick das allegorische Schreiben selbst betraf und den ,Körper' sprachlicher Darstellung affizierte. Bevor ich diese These näher entfalte, soll jedoch zunächst mit Walter Benjamins Allegoriekonzeption in Ursprung des deutschen Trauerspiels ein Sprung in die Zeit der Avantgarden vorgenommen werden. Er wird zugegeben etwas unvermittelt ausfallen, aber das hat seinen Grund in der Sache. Denn wenn bei Benjamin die barocke Allegorie als eine Spur der Avantgarde bezeichnet werden darf, dann nicht im Sinne eines Abdrucks der Geschichte, sondern als ein durch experimentelle Arbeit an der Sprache plötzlich auftauchender Präsenzeffekt, mit dessen Hilfe der Glaube an eine geschichtliche Kontinuität und Progression aus seiner teleologischen Angel gehoben wird.

2. Walter Benjamins ,Spur' der Allegorie: zur Konstellierung von Avantgarde und Barock in Ursprung des deutschen Trauerspiels

Benjamin, der sich erst spät und nach Umwegen dafür entschied, seine theoretische Fragestellung aus dem ,großen Problemkreis Wort und Begriff (Sprache und Logos)“ am Material des deutschen Trauerspiels auszuführen, ${ }^{17}$ verstand seine Arbeit selbst durchaus als einen Beitrag zum Verständnis der Avantgarde, wie die Aufzeichnungen von Asja Lacis zeigen, die Benjamin in einer Zeit traf, als dieser gerade intensiv an seinem Text arbeitete. Auf ihre verwunderte Frage, warum er sich ausgerechnet mit ,toter Literatur" des 17. Jahrhunderts beschäftige, reagierte Benjamin mit dem Hinweis auf ihren ,unmittelbaren Bezug zu sehr aktuellen Problemen der zeitgenössischen Literatur" und dem Zusatz, dass die allegorische Formsprache des Barocks eine ,analoge Erscheinung zum Expressionismus" darstelle. ${ }^{18}$ Den zeitgenössischen Rezensenten

Baltasar Gracián. El Criticón. Hg. v. Antonio Prieto. 2. Aufl. Barcelona, 1992. Zur leichteren Verständlichkeit zitiere ich im Haupttext nach der deutschen Übersetzung Baltasar Gracián. Das Kritikon. Übs. v. Hartmut Köhler. Frankfurt a. M., 2004.

17 Walter Benjamin. Briefe. Hg. v. Gershom Scholem u. Theodor W. Adorno. Frankfurt a. M., 1966, Bd. 1, S. 30.

18 Asja Lacis. Revolutionär im Beruf. Berichte über proletarisches Theater, über Meyerhold, Brecht, Benjamin und Piscator. Hg. v. Hildegard Brenner. München, 1971. Zit. n. Rolf Tiedemann u. Hermann Schweppenhäuser. „Anmerkungen der 
entging zwar weitgehend die Bedeutung von Benjamins Sprachtheorie und mit ihr auch der implizite Bezug zu den Formen der Gegenwartskunst, jene „Schleich- und Saumpfade“, die, wie Rainer Nägele es formulierte, ,zur Lektüre Baudelaires und der Moderne führen, in eine Konstellation von Texten und Lesarten, deren Gemeinsamkeit sich zunächst in der Abgrenzung von der klassisch-romantischen Ästhetik und Hermeneutik bestimmen läßt"“ ${ }^{19}$ Immerhin las jedoch schon Georg Lukács den Text zunächst als einen ,ins Barockdrama projizierten Avantgardeismus". ${ }^{20}$ Und Peter Bürger ging dann noch weiter in dieser Richtung und behauptete in seiner Theorie der Avantgarde Mitte der 1970er Jahre, Benjamins Allegoriebegriff fände ,erst im avantgardistischen Werk seinen adäquaten Gegenstand“. ${ }^{21}$ Obwohl Bürger diese Behauptung näher begründet, darf man skeptisch sein gegenüber seiner Aussage, es läge „durchaus nichts Gewaltsames in dem Versuch, den Allegoriebegriff Benjamins als eine Theorie des avantgardistischen (nicht-organischen) Kunstwerks zu lesen", wenn schon im Nachsatz eingestanden wird, dass bei diesem Verfahren „diejenigen Momente“ ausgeschlossen werden müssten, ,die sich aus der Anwendung auf die Literatur des Barock herleiten" und von diesem Ausschluss dann noch behauptet wird, er verstehe sich von selbst. ${ }^{22}$ Abgesehen davon, dass behauptete Selbstverständlichkeiten rhetorische Kunstgriffe zu sein pflegen, ignoriert Bürger damit Benjamins Anspruch, den geschichtsphilosophischen Wahrheitsgehalt der behandelten Phänomene durch Versenkung in ihren Sachgehalt zu gewinnen. Vor allem verfehlt seine Inanspruchnahme von Gewaltlosigkeit für die eigene Benjaminrezeption aber gerade dessen Gewaltbegriff. Gewalt durchzieht das Trauerspielbuch ja nicht nur metaphorisch, sondern wird dort von Anfang an als grundlegender Zug des Ideellen ausgewiesen, wenn im erkenntniskritischen Vorwort die Wahrheit der Idee als „das Wesen der Empirie erst prägende Gewalt" definiert wird. ${ }^{23}$ Damit schließt Benjamin nicht nur an die sprachphilosophischen Refle-

Herausgeber: Ursprung des deutschen Trauerspiels“. Walter Benjamin. Gesammelte Schriften. 7 Bde. Hg. v. dens. Frankfurt a. M., 1974, Bd. I.3, S. 879.

19 Rainer Nägele. „Das Beben des Barock in der Moderne. Walter Benjamins Monadologie“. Modern Language Notes 3 (1991), S. 503.

$20 \mathrm{Zu}$ dieser Einschätzung Lukács und seiner später modifizierten Haltung vgl. Gerhard Scheit. „Der Totenkopf als Messias? Ursprung und Modernität der Allegorie bei Walter Benjamin und Georg Lukàcs“. Weimarer Beiträge 12 (1989), S. 1975 f.

21 Peter Bürger. Theorie der Avantgarde. Frankfurt a. M., 1974, S. 93.

22 Ebd.

23 Walter Benjamin. „Ursprung des deutschen Trauerspiels“. Gesammelte Schriften. Hg. v. Rolf Tiedemann u. Hermann Schweppenhäuser. Frankfurt a. M., 1974, Bd. I.1, S. 216. 
xionen an, die er in seinem Aufsatz Über Sprache überhaupt und über die Sprache des Menschen entwickelt hatte, ${ }^{24}$ sondern greift auch die Idee einer ,reinen' Gewalt auf, die ihn an Georges Sorel faszinierte und die er in seiner Kritik der Gewalt bis zur messianisch-mystischen Vorstellung einer „göttlichen“ und „waltenden“ Gewalt steigerte, die sich nicht nur der Sphäre des Rechts, sondern auch der des „bloßen Lebens“ entziehe. ${ }^{25}$ Anders als der Literaturhistoriker Bürger hatte der Kunstphilosoph Benjamin keine prinzipielle Berührungsangst vor der Gewalt, solange sie als Härte der Auslegung auf die kritische Erhellung des Gegenstandes bezogen war. ${ }^{26}$ Extremismus ist ihm eine methodische Haltung und Element des Kritischen und verschafft dem Trauerspielbuch erst seine eigentümliche Form: Während die literaturhistorische Abhandlung, so Benjamin, ,die Differenzen und Extreme [...] ineinander überführt und als Werdendes relativiert" seien diese zur philosophischen Begriffsbildung als komplementäre Energien notwendig: „Notwendig werden der Kunstphilosophie die Extreme, virtuell der historische Ablauf". ${ }^{27}$ Benjamins Umgang mit den historischen Dramentexten ist dementsprechend alles andere als ein Versuch zur behutsamen Horizontverschmelzung im Dialog zwischen Vergangenheit und Gegenwart. Seiner Bestimmung von Kritik als „Mortifikation der Werke“ ${ }^{628}$ folgend behandelt er sein historisches Textkorpus - das er selbst im Übrigen als ein

24 Benjamin selbst äußerte in einem Brief an Scholem die Ansicht, die erkenntnistheoretische Einleitung der Arbeit stelle ,so eine Art zweites, ich weiß nicht, ob besseres, Stadium der frühen Spracharbeit“ dar, ,als Ideenlehre frisiert“. Benjamin (Anm. 17), Bd.1, S. 372. Winfried Menninghaus konnte ausgehend von dieser Selbsteinschätzung Benjamins den sprachphilosophischen Gehalt von Benjamins Trauerspielbuch in überzeugender Weise profilieren: Vgl. Winfried Menninghaus. Walter Benjamins Theorie der Sprachmagie. Frankfurt a. M., 1991, S. 79-134.

25 Walter Benjamin. „Zur Kritik der Gewalt“. Gesammelte Schriften. Hg. v. Rolf Tiedemann u. Hermann Schweppenhäuser. Frankfurt a. M., 1977, Bd. II.1, S. $202 f$. Das Aufgreifen Sorels in Benjamins Kritik der Gewalt habe ich in Kontrast zu Carl Schmitts Sorel-Rezeption bereits analysiert. Vgl. Hanno Ehrlicher. Die Kunst der Zerstörung. Gewaltphantasien und Manifestationspraktiken. Berlin, 2001, S. 52-66.

26 „Ohne Härte geht es bei keiner Auslegung, geschweige denn der theologischen ab. Sie kann die dichterische Fügung sprengen, um so zu mächtigeren Grundgehalten vorzustoßen und doch zugleich dem Text im Wortkern die fruchtbarste Entfaltung angedeihen zu lassen; sie kann theologisch sein, ohne die Philologie darum preiszugeben“. Walter Benjamin. „Privilegiertes Denken. Zu Theodor Haeckers ,Vergil““. Gesammelte Schriften. Hg. v. Rolf Tiedemann u. Hermann Schweppenhäuser. Frankfurt a. M., 1972, Bd. III, S. 316.

27 Benjamin (Anm. 23), S. 218.

28 Ebd., S. 357. Vgl. auch den Brief an Florens Christian Rang vom 9. Dezember 1923. Benjamin (Anm. 17), Bd. 1, S. 323. 
„merkwürdig - ja, unheimlich - schmal[es]“" Fundament einschätzte ${ }^{29}$ nicht als organische Ganzheit, die es als solche zu bewahren und zu verstehen gelte, sondern als Gegenstand der Konstruktion, als verfügbares Material, aus dem sich ohne Rücksicht auf den Ausgangskontext Zitate isolieren lassen, die dann als Elemente in die eigene spannungsvolle und erst dadurch erkenntnisbefördernde Werk-Konstellation integriert werden können. Die „Zerstückelung“ des Sinns und der Sprache, die Benjamin als Wirkung des entseelenden melancholischen Blicks des Allegorikers beschreibt, ist nicht nur Analyse eines geschichtlichen Phänomens, das dem analysierenden Subjekt äußerlich wäre, sondern auch und vor allem Selbsterkenntnis dieses Subjekts und Darstellung seiner eigenen epistemologischen Lage:

Wird der Gegenstand unterm Blick der Melancholie allegorisch, läßt sie das Leben von ihm abfließen, bleibt er als toter, doch in Ewigkeit gesicherter zurück, so liegt er vor dem Allegoriker, auf Gnade und Ungnade ihm überliefert. [...] an Bedeutung kommt ihm das zu, was der Allegoriker ihm verleiht. Er legt's in ihn hinein und langt hinunter: das ist nicht psychologisch sondern ontologisch hier der Sachverhalt. In seiner Hand wird das Ding zu etwas anderem, er redet dadurch von etwas anderem und es wird ihm ein Schlüssel zum Bereiche verborgenen Wissens, als dessen Emblem er es verehrt. ${ }^{30}$

So setzt Benjamin etwa, um nur ein Beispiel allegorischer Zerstückelungspraxis anzuführen, das für unseren Zusammenhang besonders interessant ist, Graciáns Begrifflichkeit der „ponderación misteriosa“ als Titel des fulminanten letzten Abschnitts ein, in dem die Allegorie, die kurz zuvor als das „Schema der Verwandlung“ bestimmt wurde, ${ }^{31}$ das gefallene Subjekt im „leeren Abgrund des Bösen“, in den es der Wissenstrieb geführt hat, einholt und seine Fallrichtung umkehrt zum errettenden apotheotischen Aufstieg. Das im Wissen heillos gefallene Subjekt wird dank eines plötzlichen „Eingreifen Gottes ins Kunstwerk“ - so übersetzt Benjamin die „ponderación mysteriosa“ - erhoben und zum Teil eines ideellen Sternenbildes in dem Sinne, in dem Benjamin schon in der erkenntnistheoretischen Vorrede davon gesprochen hatte. ${ }^{32}$ Graciáns spani-

29 Benjamin (Anm. 17), Bd. 1, S. 327.

30 Benjamin (Anm. 23), S. 359.

31 „Wie Alchimie und Rosenkreuzerei, wie die Beschwörungen in den Trauerspielen es beweisen, war diese Zeit nicht minder als die Renaissance der Magie ergeben. Was immer sie ergreift, verwandelt ihre Midashand in ein Bedeutendes. Verwandlung aller Art, das war ihr Element; und deren Schema war Allegorie." Ebd., S. 403.

32 „Die Ideen verhalten sich zu den Dingen wie die Sternbilder zu den Sternen. Das besagt zunächst: sie sind weder deren Begriffe noch deren Gesetze. Sie dienen nicht der Erkenntnis der Phänomene und in keiner Weise können diese Kriterien für den Bestand der Ideen sein. Vielmehr erschöpft sich die Bedeutung der Phänomene für 
sche Wortfügung ist von Benjamin dabei ganz bewusst als Fremd- und Rätselelement eingesetzt, als ein dunkel bleibender Begriff, mit dem sich der geplante „Eingriff“ ins Kunstwerk besser bewerkstelligen lässt. Zwar belegt Benjamin in einer Fußnote seine Quelle, die bekannte Abhandlung Karl Borinskis über Die Antike in Poetik und Kunsttheorie, lässt damit aber sowohl den Autor des Begriffes ungeklärt als auch den ursprünglichen Kontext der Begriffsprägung, den sechsten Discurso der Agudeza $y$ arte de ingenio, in dem die ,ponderación misteriosa“ keineswegs die emphatisch-religiöse und eschatologische Dimension besitzt, die Benjamin ihr zuschreibt, sondern als eine Technik des humanen Ingeniums beschrieben ist, der auf das Fehlen offensichtlichen Sinns mit der Findung hintersinniger erklärender Verbindungen zu reagieren vermag. ${ }^{33}$ GraciánKenner hat eine solche Ignoranz des Originals ,enttäuscht' und historisch argumentierenden Philologen dürfte sie sogar ein Ärgernis sein. ${ }^{34}$ Ihre Enttäuschung darüber, dass an dieser Stelle nichts den Gebrauch der Worte Graciáns autorisiert als Benjamins Wille zur Konstellation, missversteht aber die avantgardistisch-revolutionäre Pointe der allegorischen Zerstückelung, wie sie hier ins Werk gesetzt ist: dass man nur „Manns genug“" sein muss, ,,das Kontinuum der Geschichte aufzusprengen“ und ein messianischer Glaube an den kommenden Gott dabei nicht aus der Geschichte begründet, ${ }^{35}$ sondern begrifflich gegen sie eingesetzt werden

die Ideen in ihren begrifflichen Elementen. [...] Die Ideen sind ewige Konstellationen und indem die Elemente als Punkte in derartigen Konstellationen erfaßt werden, sind die Phänomene aufgeteilt und gerettet zugleich." Ebd., S. 214f.

33 Baltasar Gracián. Agudeza y Arte de Ingenio. 2 Bde. Hg. v. Evaristo Correa Calderón. Madrid, 1987, Bd. I, S. 88-99.

34 So José Muñoz-Millanes, der Graciáns Konzeption der „ponderación misteriosa“ erläutert und Benjamin wegen der Fehlerhaftigkeit der herangezogenen Quelle Borinskis in Schutz nimmt. Vgl. José Muñoz-Millanes. „La presencia de Baltasar Gracián en Walter Benjamin“. Al margen de Baltasar Gracián (en su IV Centenario). Hg. v. Aurora Egido. Madrid, 2001, S. 287-297. Borinski mangelnde Wissenschaftlichkeit anzulasten, um Benjamin zu entlasten, scheint mir an dieser Stelle einigermaßen absurd. Vielmehr ist der souveräne Umgang mit den Quellen hier eine Konsequenz der Benjamin'schen Konzeption von Kritik, die Gewalt an der empirischen Geschichte nicht nur in Kauf nimmt, sondern geradezu fordert.

35 „Auf den Begriff einer Gegenwart, die nicht Übergang ist sondern in der die Zeit einsteht und zum Stillstand gekommen ist, kann der historische Materialist nicht verzichten. Denn dieser Begriff definiert eben die Gegenwart, in der er für seine Person Geschichte schreibt. Der Historismus stellt das ,ewige“ Bild der Vergangenheit, der historische Materialist eine Erfahrung mit ihr, die einzig dasteht. Er überläßt es anderen, bei der Hure ,Es war einmal' im Bordell des Historismus sich auszugeben. Er bleibt seiner Kräfte Herr: Manns genug, das Kontinuum der Geschichte aufzusprengen.“ Walter Benjamin. „Über den Begriff der Geschichte“. Gesam- 
muss, um wirksam werden zu können. Auch wenn Benjamin ein solches ,revolutionäres' messianisches Bewusstsein erst später, in seiner , materialistischen' Phase explizit für sich in Anspruch nahm, prägt es - als Idee der über das Empirische, waltenden' Gewalt - seine Schriften doch von Anfang an. Die Widerstände der Philologen, auf die das Trauerspielbuch seit seinem Erscheinen traf und die bis heute anhalten, ${ }^{36}$ erklären sich nicht zuletzt als Widerstand gegen ein solches Eingreifen in die Geschichte, das sowohl mit der Tradition des humanistischen Umgangs mit den Texten bricht als auch mit der historistischen Tendenz zur Monumentalisierung des Vergangenen. Produktionsästhetisch und ideologisch steht Benjamin so in der Tat in der Nähe des Avantgardisten, wie ihn Bürger schildert, denn er schafft sein Werk nicht mehr als ein organisches Ganzes, sondern montiert es aus Fragmenten. ${ }^{37}$

Das bedeutet aber gerade nicht, dass der von Benjamin entworfene Begriff der Allegorie besonders gut für die Beschreibung konkreter avantgardistischer Kunstwerke geeignet wäre, wie er umgekehrt auch nicht notwendig bei der Analyse historischer allegorischer Werke des Barock weiterhilft. Er ist überhaupt nicht als Beschreibungskategorie gedacht, die für ein spezifisches historisches Phänomen passen könnte, sondern als Mittel zur Konstruktion einer spannungsgeladenen, das geschichtliche Kontinuum sprengenden Monade, als die Benjamin bereits im Trauerspielbuch seine Idee von der „Idee“ definierte ${ }^{38}$ und an der er auch als historischer Materialist weiter festhielt. ${ }^{39}$

Jeder Versuch, Benjamins Allegoriebegriff zu einer bloß beschreibenden Interpretation nutzen zu wollen, wäre ein philologisches Missverstehen seiner Kunstphilosophie, das ihren Anspruch entschärft. Es kann nicht verwundern, dass er sich weder ganz auf die Vergangenheit des Barock noch ganz auf die Weimarer Erfahrung des politischen und

melte Schriften. Hg. v. Rolf Tiedemann u. Hermann Schweppenhäuser. Frankfurt a. M., 1974, Bd. I.2, S. 702.

36 Vgl. dazu Uwe Steiner. „Allegorie und Allergie. Bemerkungen zur Diskussion um Benjamins Trauerspielbuch in der Barockforschung“. Daphnis 4 (1989), S. 641-670.

37 Bürger (Anm. 21), S. 95.

38 „Die Idee ist Monade - das heißt in Kürze: jede Idee enthält das Bild der Welt. Ihrer Darstellung ist zur Aufgabe nichts Geringeres gesetzt, als dieses Bild der Welt in seiner Verkürzung zu zeichnen."Benjamin (Anm. 23), S. 228.

39 „Der historische Materialist geht an einen geschichtlichen Gegenstand einzig und allein da heran, wo er ihm als Monade entgegentritt. In dieser Struktur erkennt er das Zeichen einer messianischen Stillstellung des Geschehens, anderes gesagt, einer revolutionären Chance im Kampfe für die unterdrücke Vergangenheit." Benjamin (Anm. 35), S. 703. Zu Benjamins Monadologie sei noch einmal auf die Arbeit Nägeles (Anm. 19) verwiesen. 
künstlerischen Extremismus übertragen lässt, zwischen denen er ausgespannt ist und deren polare Energien er zur Konstruktion einer eigenen Monade nutzt. So verfehlt eine direkte Anwendung deshalb sein muss, so verfehlt wäre es auch, Benjamins avantgardistische Allegoriekonzeption als idiosynkratische subjektive Wunschprojektion abzutun und sie nicht als eine relevante geschichtliche Form ernst zu nehmen. Wenn im Folgenden Graciáns allegorische Anatomie mit ihr in Verbindung gebracht werden kann, so nur unter der methodischen Benjamin'schen Prämisse, die Extreme nicht zu relativieren, sondern daraus Spannung zu gewinnen. ${ }^{40}$

3. „Moral anatomía del hombre“: Allegorische Zerstückelung in Baltasar Graciáns Criticón

Benjamin gewann seinen Begriff der Allegorie aus dem schmalen Material des deutschen Trauerspiels und der Erfahrung eines politischen Extremismus, die eben nicht nur seine persönliche war, sondern eine kollektive. Während die Kenntnis des allegorischen Theaters von Pedro Calderón de la Barca die Arbeit am Material des Trauerspielbuchs dabei formal entscheidend beeinflusste, ${ }^{41}$ war der andere von Benjamin überaus geschätzte Autor des spanischen Barock, Gracián, mit seinem Oraculo manual eher prägend für ein Ethos der „kalten persona“, das Benjamin mit Bertold Brecht und anderen Intellektuellen der Weimarer Neusachlichkeit verband. ${ }^{42}$ Das narrative Haupt- und Spätwerk Graciáns, das

40 Ich situiere mich in meinem eigenem Umgang mit dem Trauerspielbuch damit zwischen der ,vernichtenden' Kritik Benjamins durch Bernd Witte (Walter Benjamin. Der Intellektuelle als Kritiker. Stuttgart, 1976) und der ,rettenden' Kritik Winfried Menninghaus'. Gegen Witte wäre mit Menninghaus darauf zu bestehen, dass vor einer Denunziation als Idiosynkrasie zunächst der verallgemeinerbare Erfahrungsgehalt von Benjamins metaphysischer Begrifflichkeit zu erkunden wäre (Menninghaus (Anm. 24), S. 134), gegen Menninghaus, dass die gelehrte Versenkung in die Immanenz des Benjamin'schen Werkes nicht der einzig legitime Umgang damit ist. Eine lediglich fragmentarische Lektüre kann den philosophischen Gehalt des Textes zwar nicht erfassen, ist aber immerhin durch das interpretatorische Vorbild des Autors, dem eine Heiligung des Textganzen selbst ja durchaus fremd war, autorisiert.

41 So entscheidend, dass Benjamin Gershom Scholem gegenüber gar von Calderón als dem „virtuelle(n) Gegenstand“ des Trauerspielbuchs sprach. Vgl. Benjamin (Anm. 17), Bd. 1, S. 366 (Brief vom 22. Dezember 1924).

42 Vgl. Helmut Lethen. Verhaltenslehren der Kälte. Lebensversuche zwischen den Kriegen. Frankfurt a. M., 1994, bes. S. 53-70. Lethen hat inzwischen in einem Artikel mit Erdmut Wizisla auch nachweisen können, dass Brecht ein sehr aufmerksamer Leser Graciáns war, dessen Handorakel er von Benjamin erhielt: Helmut Lethen u. Erdmut Wizisla. ,,Das Schwierigste beim Gehen ist das Stillestehn“. Ben- 
1651, 1652 und 1657 in drei Teilen erschienene Criticón, kannte Benjamin ganz offenbar nicht, was wahrscheinlich schlicht daran lag, dass Arthur Schopenhauer den Text nur in einer einzigen Episode übertragen hatte und er bis 1957 im Deutschen überhaupt nur in der verhältnismäßig schwer zugänglichen alten Übersetzung Caspar Gottschlings vorlag. ${ }^{43}$ Der Text hätte ihn aber vermutlich interessiert, verbindet sich doch gerade dort das höfisch-politische persona-Ideal mit der barocken Technik allegorisch-emblematischer Darstellung, deren kunst- und geschichtsphilosophischen Gehalt Benjamin im Trauerspielbuch zu bergen versucht hatte.

Graciáns narrative Allegorik kann mit den allegorischen Inszenierungen des Dramas sicher nicht gleichgesetzt werden. Eine erste und wesentliche Affinität zu Benjamins Allegorie-Begriff besitzt sie gerade in ihrem universellen Anspruch und der Tatsache, dass sie sich nicht auf eine spezifische literarische Repräsentationstechnik beschränken lassen oder an eine bestimmte Gattung gebunden sein will. Sie zielt vielmehr über konkrete Realisierungsformen hinaus auf ein allegorisch konstituiertes Subjekt. In der direkten Adressierung des Autors an den Leser offeriert Gracián diesem seine „filosofía cortesana“ bzw. „Weltenhofbetrachtung“, wie Hartmut Köhler übersetzt, als „,curso de tu vida en un discurso“, als „Gang deines Lebens im Gedankengang“. ${ }^{44}$ Narrative Sujetbildung soll, nimmt man die Aussage ernst, mit der ethischen Selbstformung des Menschen identisch sein - ein fundamentaler Anspruch, an dem die ebenso zahlreichen wie kontradiktorischen Bemühungen der Forschung, Graciáns Criticón einer bestimmten Gattungstradition zuzuordnen, ${ }^{45}$ vorbeigehen. Der Text des Criticón, der sich schon durch das Steigerungsmorphem des Titels von der Tradition einer konkret objekt-

jamin schenkt Brecht Gracián“. Brecht Yearbook/Das Brecht-Jahrbuch 23 (1998), S. 142-146.

43 Einen kurzen Abriss der Übersetzungsgeschichte liefert Hartmut Köhler (vgl. Gracián, 2004 (Anm. 16), S. 947f.). Zur Übersetzungsgeschichte Graciáns in Deutschland allgemein vgl. auch Sebastian Neumeister. „Gracián en Alemania“. Baltasar Gracián. Selección de estudios, investigación actual y documentación. Hg. v. J. M. Ayala. Barcelona, 1993, S. 121-125.

44 Gracián 1992 (Anm. 16), S. 5 sowie ders. 2004 (Anm. 16), S. 11. Köhler übersetzt hier als „Gang deines Lebens als Gedankengang“ und nimmt damit Graciáns Kurzschluss von Leben und Diskurs die Kühnheit.

45 Einen Überblick zum aktuellen Stand der Criticón-Forschung bietet Carlos Vaíllo. „El Criticón“. Baltasar Gracián. Estado de la cuestión y nuevas perspectivas. Hg. v. Aurora Egido u. María Carmen Marín. Saragossa, 2001, S. 103-116. Zur Diskussion um Gattungszugehörigkeit und mögliche „Modelle“ vgl. ebd., S. 105ff. sowie Javier García Gibert. „En torno al género de El Criticón (y unos apuntes sobre la alegoría)“. Baltasar Gracián. El discurso de la vida. Hg. v. Jorge M. Ayala. Barcelona, 1993, S. 104-115. 
gebundenen satirischen Sittenkritik abzuheben versucht, ${ }^{46}$ ist deshalb mehr als nur ein Sammelbecken verschiedener Themen und Traditionen und von rein enzyklopädisch-kummulativer Größe wie z. B. die humanistische Silva de varia lección (1540) Pedro de Mexías. ${ }^{47}$ In ihrer Not zur richtigen Einordnung des Textes, dem eine klare Gattungsdominante (griechischer bzw. ,byzantinischer' Abenteuerroman, novela picaresca, Ritterroman a lo divino u. ä.) offenbar fehlt, ist die Forschung schließlich auch auf den Einfall verfallen, den Text als eine „Anatomie“ im Sinne Northrop Fryes zu bezeichnen, der diese Kategorie mit Blick auf Burtons Anatomy of Melancholy etablierte, um mit ihr alle diejenigen Prosatexte zu bezeichnen, die sich durch ihren analytischen Duktus auszeichneten und ihre Figuren nicht zu Charakteren ausgestalteten, sondern sie als ,"mouthpieces of the ideas they represent" benutzten, ${ }^{48}$ also allegorisch im engeren und landläufigen Sinne von Allegorie als einer konkretisierenden Personifizierung abstrakter Vorstellungen. Statt auf diesem Wege die Anatomie als Metapher zu nutzen, um einem Text, der von seinem Autor ausdrücklich als Proliferation unterschiedlicher Gattungs- und Erzählmuster offeriert wird, ${ }^{49}$ doch noch wenigstes termino-

46 Dass sich Gracián des Neuerungswertes seiner Wortbildung bewusst ist, zeigt seine Vermutung, der Titel könne Stirnrunzeln (ceño) beim Leser verursachen.

47 Pedro Mexía. Silva de varia lección. 2 Bde. Hg. v.. Antonio Castro. Madrid, 1989.

48 Northrop Frye. Anatomy of Criticism. Princeton, 1957, S. 309. Zur näheren Bestimmung der anatomy als einer Kategorie der Prosaerzählung neben novel, romance und confession vgl. ebd., S. $311 \mathrm{ff}$.

49 Gracián profiliert die Identität seines Textes in der Vorrede an den Leser durch eine Häufung von Modellen, die alle in ihn Eingang gefunden hätten: „Aus allen Autoren mit gutem Genius war ich nachzuahmen bedacht, was immer mir zusagte: aus Homer die Allegorien, aus Äsop die Fabeln, das Lehrreiche aus Seneca, das Scharfsinnige aus Lukian, aus Apuleius die Beschreibungen, aus Plutarch die Moral, aus Heliodor die Verwicklungen, aus Ariost die Unterbrechungen, aus Boccalini die Krisen und aus Barclay die Bissigkeiten." Gracián 2004 (Anm. 16), S. 11f. Statt eines der hier angesprochenen Modelle zu privilegieren und eine dominante Filiationslinie ausmachen zu wollen, scheint es mir angemessener, den Gestus des Überbietens ernst zu nehmen und ihn als Identitäts-Wucher zu begreifen. Dem Wuchern des Autors mit einer Unzahl von geistigen ,Vätern' entspricht dann konsequenterweise ein Text, der nicht mehr durch eine zentrale ideelle Funktion des Allegorischen gekennzeichnet ist, sondern durch eine Proliferation von polymorphen Gestaltungen des Allegorischen selbst. Miguel Romera-Navarro listete nicht weniger als 73 Allegorien auf. Vgl. Miguel Romera-Navarro. „Las alegorías del Criticón“. Hispanic Review 1, 1941, S. 151-175. Und Theodore L. Kassier musste feststellen, dass sich die Vielzahl konzeptistischer ,,ideas“ nicht zu einem „coherent whole or what might be considered a consistent philosophical system" zusammenfügen lassen. Vgl. Theodore L. Kassier. The Truth Disguised. Allegorical Structure and Technique in Graciáns „,Criticón“. London, 1976, S. 133. 
logisch eine generische Identität zu verleihen, soll im Folgenden versucht werden, Anatomie als einen spezifischen Blick auf den Körper zu verstehen und die funktionale Reichweite zu untersuchen, die dieser Blick als ein mögliches epistemologisches Modell des Textes besitzt.

Dass der anatomische Blick im Criticón nicht nur marginalen Stellenwert besitzt zeigt sich bereits in der Tatsache, dass er nicht auf die Crisis beschränkt bleibt, die ausdrücklich der moralischen Antomie des Menschen gewidmet ist (I.9). Auch über diese Passage hinaus ist die schiere Häufung von Bildern des fragmentierten Körpers über den ganzen Text hinweg bemerkenswert. Der moralischen Anatomie des Menschen im ersten Teil steht so nicht nur die allegorische Geschichte vom Testament des Mutes (Valor) im zweiten Teil zur Seite (II.8), ${ }^{50}$ sondern auch der Auftritt allegorischer Begleitfiguren, die einen einzigen Körperteil figurieren oder besonders prominent hervorheben wie Argos moral, der ,ganz Auge“ ist (II.1) oder der Sesudo, der eben nicht nur der „Vernunftete“ ist, sondern auch ,ganz Hirn“ (III.6). ${ }^{51}$ Und zu diesen allegori-

50 Die einzelnen Organe des Leichnams von Valor gehen dabei auf unterschiedliche Nationen über. Die Spanier gehen zwar leer aus, erhalten aber als Vermächtnis des Mutes die Erlaubnis, alle anderen mit Krieg zu überziehen und sie niederzuwerfen, was sie dann mit Erfolg tun und sich so ,zur vollen Größe der Tapferkeit erheben“. Gracián 2004 (Anm. 16), S. 469. Abgesehen von der offensichtlichen ideologischen Funktion der Passage, das Großmachtstreben der spanischen Monarchie zu rechtfertigen, ist bemerkenswert, dass Gracián dabei die antike Tradition politischer Herrschaftslegitimation über eine naturalisierende Organismus-Analogie nicht bruchlos übernimmt, sondern der Legitimation eine spezifisch christliche Wendung gibt. Anders als in der bekannten Fabel vom Bauch und den Gliedern bei Titus Livius wird politische Macht hier nicht durch eine mythische Erinnerung an eine ursprüngliche organische Einheit fundiert, sondern im Gegenteil als ein diskursiv gestifteter Restitutionsauftrag dargestellt, mit dem eine verlorene Einheit retroaktiv wiederhergestellt wird. Die christliche Pointe der Erzählung liegt gerade darin, dass sich die Macht der spanischen Monarchie nicht aus der körperlichen Natur herleiten muss, sondern gegen sie begründet ist. Einer immer schon ,toten' körperlichen Natur (der an sein biologisches Ende gekommene Valor) verleiht erst der somatische Leib einer militanten christlichen Gemeinschaft nachträglich ihren symbolischen Sinn. Zur Tradition der organologischen Gesellschaftsmetaphorik vgl. Susanne Lüdemann. Metaphern der Gesellschaft. Studien zum soziologischen und politischen Imaginären. München, 2004, S. 79-100. Zur Kritik der in dieser politischen Fabel waltenden rassistischen und misogyn-körperfeindlichen Ideologie vgl. Paul Julian Smith. Representing the Other. ,Race; Text, and Gender in Spanish and Spanish American Narrative. Oxford, 1992, S. 85ff. („El Criticón, Allegory and Nationality").

51 Gracián 2004 (Anm. 16), S. 748, muss die Semantik von „seso“ reduzieren und entscheidet sich dafür, das Seelenvermögen der Vernunft (sensus) und nicht das ihm zugeordnete materielle Organ (Hirn) hervorzuheben. Da „seso“ im Spanischen beides bedeutet (,Seso, llamamos la médula de la cabeza o celebro“ hält Covarru- 
schen Körper-Teilen lassen sich noch eine Fülle über das Gesamtkorpus verstreuter Bilder vom Körper anführen, die ihn insgesamt als zerstückelten oder in seiner Einheit bedrohten erscheinen lassen, ,fragmented, menaced by poison or animals, hollowed out, suspended, and mutated", wie Paul Julian Smith zu Recht konstatierte. ${ }^{52}$ Die Frage, die sich anschließen muss, ist die nach der Funktion einer solchen allegorischen Zerstückelung. In Benjamins Trauerspielbuch ließ sie sich grundsätzlich als Instrument einer Idee bestimmen: Die Allegorie leistet dort die erkenntnistheoretisch begründete Aufteilung und Zerstreuung der Phänomene im Begriff, die als Voraussetzung für die Möglichkeit zur Konstellation fungiert, in der sich dann die ,prägende Gewalt" der Idee realisieren kann. Der Primat des Allegorischen, den Benjamin an Calderóns Dramen beeindruckte, ${ }^{53}$ führte im Trauerspielbuch zur Mortifizierung der behandelten dramatischen Werke und der Ausstellung der Leiche als ihrem „obersten emblematischen Requisit“ schlechthin, ${ }^{54}$ in das sich der Melancholiker immer wieder versenkt. Zerstückelt wird beim „Blick in die Sprachtiefe ${ }^{\text {،55 }}$ zwar die ,Lebendigkeit' der Sprache, insofern deren Mitteilungsfunktion ganz aufgelöst wird, aber der analytische Blick von Benjamins allegorischem Melancholiker ist nicht wirklich anatomisch zu nennen, da er nie das Material des Körpers anvisiert und dessen Detailreichtum beobachtbar macht. Graciáns Allegorik dagegen basiert auf einem somatischen Fundament und stellt immer wieder die Materialität eines Körpers aus, der nicht auf seine endliche und nichtige Bedeutung als Leiche reduziert bleibt, sondern auch in seiner empirischen Gegenständlichkeit, als Nase, Auge, Kopf oder Hirn sichtbar gemacht wird. Der kontinuierliche Auftritt von Körperteilen im Text des Criticón ist umso bemerkenswerter, als er das idealistische platonische Körperbild unterläuft, das die ,anatomia moral del hombre“ zunächst aufruft und zu affirmieren scheint, wenn sie den Kopf als höchstes Organ des Menschen betont und ihm innerhalb des Körperaufbaus eine Sonderstellung einräumt:

„Den Kopf", sagte Andrenio, „möchte ich gerne - aber vielleicht irre ich mich - Alkazar der Seele nennen, Hofburg ihrer Kräfte und Fähigkeiten.“

bias Tesoro de la Lengua Castellana o española von 1611 als zweite Wortbedeutung fest), ist der Ausdruck wesentlich plastischer und entspricht dem anatomischen Blick, der Körper-Teile isoliert.

52 Smith (Anm. 50), S. 92.

53 Benjamin (Anm. 23), S. 402.

54 Ebd., S. 392.

55 Ebd., S. 376. 
„Du hast Recht“, bestätigte Artemia, „denn gleich wie Gott zwar überall zugegen ist, mit Besonderheit jedoch im Himmel, wo seine Größe sich entfaltet, so stellt sich auch die Seele an diesem erhöhten Ort, dem Abbild der Himmelskugel zur Schau." ${ }^{\text {56 }}$

Dass Graciáns moralische Anatomie nicht einfach dem platonische Entwurf vom Menschen als mikrokosmischem Abbild des schönen göttlichen Kosmos folgt, wie er im Timaois formuliert und im christlichen Neoplatonismus - in Spanien z. B. von Fray Luis de Granada - wiederholt wurde, lässt schon die Wortwahl vom „Alkazar der Seele“ erahnen. Der platonische Idealismus ist zur umlagerten Festung geworden, das begriffliche Wissen von der wahren Ontologie der Welt vom permanenten Ansturm des wahrnehmbaren, aber unwahren Somatischen bedroht. Angesichts der Tatsache, dass Gracián der Rede Andrenios eine Spiegelszene vorausgehen lässt, darf man das vielleicht auch mit Jacques Lacan als méconnaissance des Subjekts bezeichnen, dessen imaginäres moi ideal einen konstitutiven Mangel und die Erfahrung körperlicher Unvollkommenheit verdrängt, die im Phantasma des zerstückelten Körpers symbolisch oder symptomatisch wiederkehrt. ${ }^{57}$ Der Dialog zwischen Andrenio und Artemia stellt diesen Verdrängungsmechanismus aus, indem er immer wieder den somatisch bedingten Mangel, der in der idealistischen Selbstbespiegelung des Menschen negiert werden soll, zurückkehren lässt. ${ }^{58}$ Nachdem Andrenio im narzisstischen Blick auf sich selbst als erstes die aufrechte Haltung des Menschen erkennt und Artemia dies platonisch aus der Orientierung des Menschen am Himmel erklärt, erinnert Critilos Kommentar sofort an die unschöne Wirklichkeit, von dem dieses Idealbild absehen muss:

„So ist es“, sagte Critilo. „Wo immer wir die Haltung gekrümmt finden, da vermuten wir auch die Einstellung verdreht; wo wir Buckel und Buchten am Körper finden, da fürchten wir Falten und Falschheit in der Seele; bei wem ein Auge umwölkt ist, den verblendet gewöhnlich auch die Leidenschaft [...].“. ${ }^{59}$

56 Gracián 2004 (Anm. 16), S. 159. „,- La cabeza - dijo Andrenio - llamo yo, no sé si me engaño, alcázar del alma, corte de sus potencias. - Tienes reazón - confirmó Artemia -, que así como Dios, aunque asiste en todas partes, pero con especialidad en el cielo, donde se permite su grandeza, así el alma se ostenta en este puesto superior, retrato de los celestes orbes“. Gracián 1992 (Anm. 16), S. 99.

57 Jacques Lacan. „Le stade du miroir comme formateur de la fonction du Je“. Écrits. Paris, 1999, Bd. 1, S. 92-99.

58 Der Mechanismus imaginärer Selbstverkennung scheint mir hier noch wesentlicher zu sein als der phobische Ausschluss des Anderen, auf den Smith abhebt. Jedenfalls ist die Behauptung, der Diskurs beginne ,with a gesture of exlusion“ (Smith (Anm. 50), S. 88), so nicht richtig, denn die imaginäre Spiegelszene geht der Stigmatisierung der Körperbehinderten eindeutig voran.

59 Gracián 2004 (Anm. 16), S. 158f. ,-Es así -dijo Critilo-, dondequiera que halla- 
Das ist nicht nur ein kruder Physiologismus, sondern eine glatte Inversion des platonischen Realismus, da hier von der wahrnehmbaren Welt der Erscheinungen ausgegangen und dann auf ein verborgenes Sein geschlossen wird und nicht umgekehrt. Diese Tendenz zur konkretistischen Verkörperlichung der platonischen Ideenwelt findet ihre konzeptistische Pointe wenig später, wenn Artemia Andrenios Meinung, die Haare des Menschen seien überflüssiger Ornat, korrigiert: „Sie sind die Wurzeln dieses Menschenbaumes [...]. Mit ihnen ist er im Himmel befestigt, und sie führen ihn, wie man sagt, an einem Haar ${ }^{\text {“ }} .{ }^{60}$ Die platonische Rede von der himmlischen Verwurzelung des Menschen ${ }^{61}$ wird durch die Einführung des Details der Haare nicht verfeinert und sublimer, sondern ingeniös so stark forciert, dass die Pointe die argumentative Grundlage des Systems regelrecht zu durchlöchern droht. Der Körper, den Platon als harmonische organische Einheit vorstellt, wird durch die Fokussierung auf seine Einzel-Teile grotesk, das Ähnlichkeitsverhältnis von Sein und Schein durch die konzeptistische Lust an der Zusammenführung möglichst extremer semantischer Gegensätze überspannt. Und wenn die ingeniöse agudeza an dieser Stelle tatsächlich noch im Platonismus ankern sollte, dann nurmehr am seidenen Faden hängend, „por un pelín“, um in der Sprache und Bildlichkeit Graciáns zu bleiben. Die Zersetzung des platonischen Idealismus durch die konzeptistische Arbeit am Signifikanten findet jedoch dort ihren Abschluss, wo Graciáns allegorische Menschenanatomie zu dem Organ kommt, das den ingeniösen gusto generiert.

Während im Timaois der Mund ganz ausschließlich ein Organ der vernünftigen Rede und damit dem Logos unterstellt ist, fällt Andrenio seine Doppelfunktion als Rede- und Kauwerkzeug auf:

mos corvada la disposición recelamos también torcida la intención. En descubriendo ensenadas en el cuerpo, tememos haya dobleces en el ánimo; el otro a quien se le anubló alguno de los ojos, también suele cegarse de pasión [...].“ Gracián 1992 (Anm. 16), S. 98.

60 Gracián 2004 (Anm. 16), S. 160.

61 „Was die maßgeblichste Form der Seele in uns angeht, müssen wir darüber denken, dass der Gott sie einem jeden als Schutzgeist gegeben hat, nämlich als die Form, von der wir sagen, dass sie im obersten Teil unseres Körpers wohnt und uns zu dem im Himmel, was uns verwandt ist, von der Erde erhebt, da wir kein irdisches, sondern ein himmlisches Geschöpf sind, wie wir mit größtem Recht behaupten können. denn dort, wo die erste Erschaffung der Seele sich vollzog, gab die Gottheit unserem Kopf und unserer Wurzel einen festen Ort und verlieh so dem ganzen Körper seine aufrechte Haltung." Platon. Timaios. Übs. v. Thomas Paulson u. Rudolf Rehn. Stuttgart, 2003, 90a, S. $205 f$. 
„Eines vermag ich nicht zu verstehen“, sagte Andrenio, „zu welchem Behuf nämlich die weise Natur in ein und derselben Offizin das Essen und das Sprechen verrichten lässt. Was hat das eine Geschäft mit dem anderen zu schaffen? Das eine ist eine niedere Verrichtung, findet sich auch bei den Tieren; das andere etwas Erhabenes, einzig für Personen: Zudem haben hier auch erhebliche Unzuträglichkeiten ihren Ursprung; und zwar zunächst die, dass die Zunge je nach dem Geschmack redet, der ihr bleibt, bald süß, bald bitter oder sauer oder scharf. Der Stoff der Nahrung wirkt auf sie. [...] Stünde sie nicht besser allein für sich, als reines Orakel des Geistes? “62

Ein echtes Rätsel, wie auch Critilo ausdrücklich betont (,du verschwierigst gut") und damit genau das, was für Gracián die ponderación misteriosa notwendig macht. An dieser Stelle kommt nun die Vorsehung ins Spiel, was ganz außergewöhnlich für diesen Text ist, der sonst frei bleibt von direkten Thematisierungen des Glaubens:

Wenn ich bedenke, dass die Natur von der höchsten Vorsehung durchherrscht ist, so finde ich den großen Vorteil im Zusammengehen des Geschmack mit dem Sprechen darin, dass der Geschmack die Worte prüfen kann, bevor er sie ausspricht; kauen sollte er sie jedesmal, und kosten, ob sie auch nahrhaft sind; und merkt er, dass sie bitter schmecken, so mag er sie getrost versüßen. [...] Ein wenig Überzuckern kann nicht schaden. Die Zunge soll sich nur immer mit dem Essen befassen, und am besten auch noch mit vielem anderen, damit sie nicht ganz und gar im Reden aufgeht. ${ }^{63}$

Dass ein jesuitischer Autor sich auf das Vorhandensein der Providenz berufen kann, wäre nicht weiter bemerkenswert. Interessant ist aber, dass er dabei der platonischen Meditation der ursprünglich-seienden Idee eine Heiligung des Sprachleibes entgegenstellt, mit der das Heilige praktisch

62 Gracián 2004 (Anm. 16), S. 172. „--Lo que yo no acabo de entender -dijo Andrenio- es a qué propósito juntó en una misma oficina la sabia naturaleza el comer con el hablar. ¿Qué tiene que ver el un ejercicio con el otro? La una es ocupación baja y que se halla en los brutos; la otra es sublime y de solas las personas. A más que de ahí se originan inconvenientes notables; y el primero, que la lengua hable según el sabor que se le pega, ya dulce, ya amargo, agrio o picante; queda muy material de la comida: y se roza, ya tropieza, habla grueso, se equivoca, se vulgariza y se relaja. ¿No estuviera mejor sola ella, hecha oráculo del espíritu?" Gracián 1992 (Anm. 16), S. 105f.

63 Gracián 2004 (Anm. 16), S. 172. „-Aguarda -dijo Critilo-, que dificultas bien y casi me haces reparar. Mas con todo eso apelando a la suma providencia que rige la naturaleza, una gran conveniencia hallo yo en que el gusto coincida con el hablar, para que de esa suerte examine las palabras antes que las pronuncie: másquelas tal vez, pruébelas si son sustanciales, y si advierte que pueden amargar, endúlcelas también; sépa a qué sabe un no y qué estómago le hará al otro: confítelos con el buen modo. Ocúpese la lengua en comer, y aun si pudiera, en otros muchos empleos, para que no toda se emplease en el hablar. Siguen a las palabras las obras; [...].“ Gracián 1992 (Anm. 16), S. 106. 
vollständig von Gott und Christus als dessen fleischgewordenen Wort auf die Materialität der menschlichen Sprache selbst transponiert wird. Wenn Graciáns moralische Anatomie des Menschen letztlich einen Sinn freisetzt, dann liegt er weniger in der theoretischen Beglaubigung einer idealen Ordnung des Organischen, in der sich die Einzel-Teile des Körpers zum selbst-identischen Sein zusammenfügen sollen, sondern im nur auf der literalen Ebene des Allegorischen zu erfahrenden, praktisch differenzierenden Geschmack der Sprache. Für Gracián überbrückt die Sprache nicht als Logos, sondern als Organ zur Kultivierung der Sinne erfolgreich die phänomenale Kluft, die zwischen den Gegenständen herrscht, und schafft jene ,ponderación misteriosa“, die Benjamin allein der überphänomenalen ,prägenden Gewalt“ des Begriffs zugestand. Am Ende des Criticóns steht denn bezeichnenderweise auch keine Apotheose des Menschenpaares Andrenio und Critilo, sondern eine letzte Allegorie, in der sich der Lebens-Diskurs als Schrift selbst zu verewigen sucht: Die zwölfte Krisis schließt mit einer Utopie der Schrift, die als einziges Heilmittel gegen das melancholische Bewusstsein vom Tod angepriesen wird. Die beiden Protagonisten erreichen auf einem Boot voller Embleme und Impresen die Insel der Ewigkeit, die von einem Meer aus Tinte umgeben ist und an sich nichts spezifisch Christliches hat. Der dort befindliche Eingang ins immerwährende Leben des Ruhmes ist noch pragmatischer durch die Schrift reguliert, denn an dieser Stelle werden Geleitbriefe nötig, die dem Verdienstrichter vorgelegt werden müssen, der den Einlass in die Ewigkeit überwacht. Eine allzu prosaische und bürokratische Auffassung von der Nützlichkeit der Schrift als einem Medium zur Verewigung des Subjektes in der kollektiven Erinnerung, als dass diese letzte Allegorie des Criticón mit Benjamins Schema der rettenden Verwandlung des Subjekts verwechselt werden könnte. Zwar will auch die Allegorik Graciáns über das endliche empirische Leben hinaus und treibt dabei durch allegorische Zerstückelung vor allem das künstliche ,Wesen' der Sprache, ihren Schriftcharakter, hervor. Aber anders als bei Benjamins sprachmagisch gewendetem Platonismus ist ihm das Wort nicht Idee und prägende Gewalt, die an die Stelle eines abwesenden Gottes tritt, sondern ein sinnlich-physischer Sprachleib, dessen Möglichkeiten zur Sinnbildung mit ingeniösem gusto geprüft und ausgekostet werden sollen. Wenn Gracián dem Geschmack diese Sinnbildungsleistung zutraut, ist er von einem doppelten Vertrauen getragen: Der gusto steht für ihn immer noch in Kommunion mit dem Transzendenten und ist metaphysisch gesichert; seine Gültigkeit wird zugleich sozial vorausgesetzt und entspricht dem Vertrauen auf gemeinsame Werte, die der Autor mit seiner gelehrten Leserschaft sicher zu teilen glaubt. Deshalb 
kann er im Vorwort zum dritten und letzten Teil des Criticón auch dem Leser die Marginalspalten für Korrekturen und Verbesserungen freihalten, ohne eine Verfälschung seiner Intentionen zu befürchten. ${ }^{64}$

Die Gestaltung des Allegorischen ist bei Gracián also (noch) nicht vom Sündenfall des Subjekts ins leere Wissen ausgehöhlt, den Benjamin aus der Wahrnehmung seiner Moderne heraus bereits im Barock beginnen lässt. Aber die vielen Teil-Allegorien, die in immer neuen Formen den Text des Criticón bevölkern und dabei durchaus einer Epistemologie des anatomischen Blicks entsprechen, fügen sich sichtbar nicht mehr zu einem Ganzen - entgegen der programmatischen Überzeugung des Autors, jede Form von Rede und Erfindung müsse sich zu einem einheitlichen Körper vollenden. ${ }^{65}$ Ganz materiell ist dem Text in seiner Präsentation monströser Teil-Köper und Körper-Teile der konstitutive Mangel abzulesen, der schon Andrenios imaginäre Selbstbespiegelung bedroht hatte. Das „Zentrum der Unsterblichkeit“, das in Analogie zu den ersten beiden Bänden als Inhalt der 13. Krisis des dritten Teils zu erwarten wäre und eine teleologische Schließung des allegorischen Corpus leisten müsste, wird nicht mehr repräsentiert, sondern bleibt der eigenen Erfahrung des Leser vorbehalten, der dafür aber über den Raum der Repräsentation hinausgehen und sein eigenes Leben einsetzen muss: „Was sie dort zu Gesichte bekamen, welche Genüsse sie dort erwarteten, wer das wissen und erfahren möchte, der gehe selbst Richtung Tugend und Vor-

64 „Muchos borrones toparás, si lo quisieres acertar: haz de todos uno. Para su enmienda te dejo las márgenes desembarazadas, que suelo yo decir que se introdujeron para que el sabio letor las vaya llenando de lo que olvidó o no supo el autor; para que corrija él lo que erró este.“ Gracián 1992 (Anm. 16), S. 372. „Manchen Makel wirst du finden, wenn du es darauf anlegst: So mache besser gleich aus allen einen. Zum Korrigieren lasse ich dir diesmal die Ränder frei, denn diese sind ja eigentlich dazu da, damit der kluge Leser ergänzt, was der Autor vergessen hat oder was ihm entging, mithin verbessert, wo jener nicht genügte." Gracián 2004 (Anm. 16), S. 598.

65 „Sola una cosa quisiera que me estimases, y sea el haber procurado observar en esta obra aquel magistral precepto de Horacio en su inmortal arte de todo discurrir, que dice: Denique sit quod uis, simplex dumtaxat et unum. Cualquier empleo del discurso y de la invención, sea lo que quisieres, o épica o cómica u oratoria, se ha de procurar que sea una, que haga un cuerpo, y no cada cosa de por sí, que vaya unida, haciendo un todo perfecto.“ Gracián 1992 (Anm. 16), S. 372f. „Nur eines hätte ich gerne, das du mir zugute hieltest, nämlich dass ich mich in diesem Werk bemüht habe, jene Meisterregel des Horaz zu beachten, die er in seiner unvergänglichen Redekunst aufstellt: Denique sit quod vis simplex dumtacat et unum. Wie immer Rede und Erfindung eingesetzt sein mögen, ob episch, komisch oder rhetorisch, es gilt dafür Sorge zu tragen, dass ein Ganzes entsteht, ein zusammenhängender Körper, dass nicht jedes Stück für sich bleibt, vielmehr alles zu einer Einheit vollendet wird." Gracián 2004 (Anm. 16), S. 598. 
trefflichkeit, Richtung Tapferkeit und Heldentum [...]." ${ }^{66}$ Die letzte Einsicht der allegorischen Anatomie Graciáns bleibt so die in eine nicht aufzuhebende Nachträglichkeit der Erkenntnis. Zum Ganzen des Lebens fehlt im Leben immer das entscheidende letzte Stück.

\section{LITERATURVERZEICHNIS}

Alberti López, Luis. La anatomía y los anatomistas españoles del Renacimiento. Madrid, 1948.

Alston, Mary N. „The Attitude of the Church Towards Dissection Before 1500“. Bulletin of the History of Medicine 3 (1944), S. 221-238.

Bachtin, Michail M. Literatur und Karneval. Zu Romantheorie und Lachkultur. Frankfurt a. M., 1990.

Benjamin, Walter. Briefe. Hg. v. Gershom Scholem u. Theodor W. Adorno. 2 Bde. Frankfurt a. M., 1966.

Benjamin, Walter. „Ursprung des deutschen Trauerspiels“. Gesammelte Schriften. 7 Bde. Hg. v. Rolf Tiedemann u. Hermann Schweppenhäuser. Frankfurt a. M., 1974, Bd. I.1, S. 203-430.

Benjamin, Walter. „Über den Begriff der Geschichte“. Gesammelte Schriften. 7 Bde. Hg. v. Rolf Tiedemann u. Hermann Schweppenhäuser. Frankfurt a. M., 1974, Bd. I.2, S. 691-704.

Benjamin. „Privilegiertes Denken. Zu Theodor Haeckers ,Vergil'“. Gesammelte Schriften. Hg. v. Rolf Tiedemann u. Hermann Schweppenhäuser. Frankfurt a. M., 1972, Bd. III, S. 315-322.

Benjamin, Walter. „Zur Kritik der Gewalt“. Gesammelte Schriften. Hg. v. Rolf Tiedemann u. Hermann Schweppenhäuser. Frankfurt a. M., 1977, Bd. II.1, S. 179-204.

Blumenberg, Hans. Die Legitimität der Neuzeit. Frankfurt a. M., 1966.

Bürger, Peter. Theorie der Avantgarde. Frankfurt a. M., 1974.

Bylebyl, Jerome J. „Interpreting the Fasciculo Anatomy Scene“. Journal of the History of Medicine 45 (1990), S. 285-316.

Cunningham, Andrew. The Anatomical Renaissance. The Resurrection of the Anatomical Projects of the Ancients. Aldershot, 1997.

Derrida, Jacques. Gesetzeskraft. Der „,mystische Grund der Autorität“. Frankfurt a. M., 1991.

Ehrlicher, Hanno. Die Kunst der Zerstörung. Gewaltphantasien und Manifestationspraktiken europäischer Avantgarden. Berlin, 2001.

Eriksson, Ruben (Hg.). Andreas Vesalius' First Public Anatomy at Bologna 1540. An Eyewitness Report. Uppsala u. Stockholm, 1959.

Frye, Northrop. Anatomy of Criticism. Princeton, 1957.

García Gibert, Javier. „En torno al género de El Criticón (y unos apuntes sobre la alegoría)“. Baltasar Gracián. El discurso de la vida. Hg. v. Jorge M. Ayala. Barcelona, 1993, S. 104-115.

66 Gracián 2004 (Anm. 16), S. 941. „Lo que allí vieron, lo mucho que lograron, quien quisiere saberlo y experimentarlo, tome el rumbo de la Virtud insigne, del Valor heroico y llegará a parar al teatro de la Fama, al trono de la Estimación y al centro de la Inmortalidad.“ Gracián 1992 (Anm. 16), S. 576. 
Gracián, Baltasar. Agudeza y Arte de Ingenio. 2 Bde. Hg. v. Evaristo Correa Calderón. Madrid, 1987.

Gracián, Baltasar. El Criticón. Hg. v. Antonio Prieto. 2. Aufl. Barcelona, 1992.

Gracián, Baltasar. Das Kritikon. Übs. v. Hartmut Köhler. Frankfurt a. M., 2004.

Hodges, Devon L. Renaissance Fictions of Anatomy. Amherst, 1985.

Kassier, Theodore L. The Truth Disguised. Allegorical Structure and Technique in Graciáns , Criticón“. London, 1976.

Lacan, Jacques. „Le stade du miroir comme formateur de la fonction du Je“. Écrits. Paris, 1999, Bd. 1, S. 92-99.

Lethen, Helmut. Verhaltenslehren der Kälte. Lebensversuche zwischen den Kriegen. Frankfurt a. M., 1994.

Lethen, Helmut u. Erdmut Wizisla. ,„Das Schwierigste beim Gehen ist das Stillestehn“. Benjamin schenkt Brecht Gracián“. Brecht Yearbook/Das Brecht-Jahrbuch 23 (1998), S. 142-146.

Lüdemann, Susanne. Metaphern der Gesellschaft. Studien zum soziologischen und politischen Imaginären. München, 2004.

Mandressi, Rafael. Le regard de l'anatomiste. Dissections et invention du corps en Occident. Paris, 2003.

Menninghaus, Winfried. Walter Benjamins Theorie der Sprachmagie. Frankfurt a. M., 1991.

Mexía, Pedro. Silva de varia lección. 2 Bde. Hg. v. Antonio Castro. Madrid, 1989.

Muñoz-Millanes, José. „La presencia de Baltasar Gracián en Walter Benjamin“. Al margen de Baltasar Gracián (en su IV Centenario). Hg. v. Aurora Egido. Madrid, 2001, S. 287-297.

Nägele, Rainer. „Das Beben des Barock in der Moderne. Walter Benjamins Monadologie“. Modern Language Notes 3 (1991), S. 501-527.

Neumeister, Sebastian. „Gracián en Alemania“. Baltasar Gracián. Selección de estudios, investigación actual y documentación. Hg. v. Jorge M. Ayala. Barcelona, 1993, S. 121-125.

Platon. Timaios. Übs. v. Thomas Paulson u. Rudolf Rehn. Stuttgart, 2003.

Romera-Navarro, Miguel. „Las alegorías del Criticón“. Hispanic Review 1 (1941), S. 151-175.

Scheit, Gerhard. „Der Totenkopf als Messias? Ursprung und Modernität der Allegorie bei Walter Benjamin und Georg Lukàcs“. Weimarer Beiträge 12 (1989), S. 19611979.

Smith, Paul Julian. Representing the Other. ,Race', Text, and Gender in Spanish and Spanish American Narrative. Oxford, 1992.

Steiner, Uwe. „Allegorie und Allergie. Bemerkungen zur Diskussion um Benjamins Trauerspielbuch in der Barockforschung“. Daphnis 4 (1989), S. 641-670.

Stockhorst, Stefanie. „Unterweisung und Ostentation auf dem anatomischen Theater der Frühen Neuzeit“". Zeitsprünge 9 (2005), S. 271-290.

Tiedemann, Rolf u. Hermann Schweppenhäuser. „Anmerkungen der Herausgeber: Ursprung des deutschen Trauerspiels“. Walter Benjamin. Gesammelte Schriften. 7 Bde. Hg. v. dens. Frankfurt a. M., 1974, Bd. I.3, S. 868-981.

Vaíllo, Carlos. „El Criticón“. Baltasar Gracián. Estado de la cuestión y nuevas perspectivas. Hg. v. Aurora Egido u. María Carmen Marín. Saragossa, 2001, S. 103-116.

van Delft, Louis. Littérature et anthropologie. Nature humaine et caractère à l'âge classique. Paris, 1993.

Witte, Bernd. Walter Benjamin. Der Intellektuelle als Kritiker. Stuttgart, 1976. 